\title{
Answers from the Holistic Transdisciplinary Paradigm to the Contemporary Challenges in Education: The Subject Awakening and Integration among Sciences, Tradition, Wisdom and Experiences
}

\author{
Camila Aloisio Alves \\ Public Health-Medical School Petrópolis (FMP), Petrópolis, Brazil \\ Email: camila.aloisioalves@gmail.com
}

Received 9 March 2016; accepted 23 March 2016; published 28 March 2016

Copyright (C) 2016 by author and OALib.

This work is licensed under the Creative Commons Attribution International License (CC BY). http://creativecommons.org/licenses/by/4.0/

(c) (i) Open Access

\begin{abstract}
The present days are marked by deep technological changes, the introduction of media and interaction resources. At the same time, these days faced different crises worldwide which were induced by pollution, irresponsible misuse of natural resources, by the social inequality maintenance and great abysms in the human development. One of the greatest challenges in the educational process is to follow these changes and to respond to them integrally, responsibly and in a way implied to results from human actions. Thus, the educational and formative processes need to overcome the knowledge exchange model and work with different ways of apprenticeship. The current paper aims to analyse the author's trajectory in a stricto sensu formation centred in holistic and transdisciplinary approaches. The autobiography was the method employed to allow the analysis of experienced change and its impacts on the author's training course. Results show that formation allows individual development in different levels and it connects them to society and nature, it becomes possible integrating sciences, knowledge and traditions to the construction of relationships and to the production of practices in different action fields, which are sensitive and awake for knowledge integrity.
\end{abstract}

\section{Keywords}

Transdisciplinary, Education, Paradigm and Teaching Learning Methodology

Subject Areas: Education

How to cite this paper: Alves, C.A. (2016) Answers from the Holistic Transdisciplinary Paradigm to the Contemporary Challenges in Education: The Subject Awakening and Integration among Sciences, Tradition, Wisdom and Experiences. Open Access Library Journal, 3: e2497. http://dx.doi.org/10.4236/oalib.1102497 


\section{Introduction}

The present days are marked by deep technological changes and the introduction of media and interaction resources which shorten distances, speed the search for information and knowledge. Over decades of study, research and knowledge production — sciences centred in the Cartesian paradigm—-left numerous legacies to humanity, thus allowing distance straightening, automatic work processes, facilitating communication, increasing life expectance through drugs, exams, diagnostics and products. The expansion of knowledge allowed individuals to explore and experience life through different perspectives, widening horizons and giving more freedom of speech and production.

At the same time, these days lived different world crises induced by pollution, irresponsible misuse of natural resources, by the social inequality maintenance and by great abysms in the human development, in different societies. Societies are going through deep changing processes as well as are questioning the way to conduct their productive, educational, cultural and economic processes. The ability to assess, measure and monitor technology impacts, ways of capitalist production and intervention were little explored. No matter if by ignorance or negligence, it makes mankind face important challenges to guarantee life maintenance.

According to Santos [1], the current moment demands developing cautious knowledge about the meaning of a decent life by means of sciences committed to the impacts and consequences of their achievements, thus reflecting on the correct use of technologies, exploring knowledge fields, wisdom and traditions.

Thus, one of the greatest challenges faced by the educational process is to follow up technological, political, cultural and social changes and hold their total responsibly for them, and also to respond in a way applicable to results from human actions.

The formative and educational processes need to overcome the knowledge exchange module focused on the cognitive intelligence to work different ways during apprenticeship, embracing other intelligences (emotional, physical and intuitive). UNESCO educational pillars [2] —learning how to know, how to make, to be and to live together-translate the challenge set to the educational field, it calls out for the methodological review of teaching and learning processes.

In order to develop knowledge contents implied to results, consequences and advances, the essential task is to transform mankind's understanding about itself and about the world surrounding it. The great paradigmatic changes nowadays call individuals out for an inner goal of overcoming, expanding and deepening visions, comprehensions and actions; thus, self-renewal will be expressed in the world.

By considering the challenge brought by this paradigmatic change to the nowadays societies, the present paper aims to analyze the author's trajectory in a stricto sensu education process centred in the holistic and transdisciplinary approach. The results were analyzed according to personal changes lived by the author during the development of new knowledge and abilities to respond to society's nowadays demands.

\section{Methodology}

The present paper used autobiography as it methodology in an attempt to understand the author's individual and social background (Bueno, 2002) as an apprentice of the Post-graduation course in Human Development-Holistic Transdisciplinary approach fostered by Universidade Internacional da Paz do Rio de Janeiro (UNIPAZ$\mathrm{RJ})^{1}$.

The autobiography, as work methodology, brings the possibility of including some subjectivity as main element of analysis in the personal transformation process through memories of personal experiences articulated with historical contexts [3] [4].

The material analysis used by the autobiographic methodology may be primary—narrative or autobiographic stories made face to face—or secondary—letters, diaries, several narratives, documents, photographs [3].

Secondary materials resulting from self-assessment achieved during the course were used in the current paper. They became resources used by UNIPAZ-RJ to assess each one of the disciplines. Such assessment may express the apprentice's comprehension about the content of the seminar according to their reflections, perceptions and changes regrading concepts and practices.

${ }^{1}$ UNIPAZ-RJ is a school of education and holistic care which adopts the holistic transdisciplinary approach as methodological basis of activities and it also adopts the pedagogical process known as The Art of living life and The Art of Taking Care. Its mission consist of allowing people and groups to reflect and experience, fact that helps individuals to find ways that enable awareness awakening, love revealing, wisdom and ethics, besides all beings. www.unipazrj.org.br 
The human action, according to Ferrarotti [3], expresses the appropriation of social relationships which, by an internalization and externalization cycle, builds psychic structures and changes the ways to exit and act in the world.

As it was stated by Ferrarotti [3], individuals act in the social world appropriation process and he-she is dream, delusion and manpower, altogether; thus, they generate the synthesis of the existence process. Individuals do not live nor build themselves alone. Their trajectories have historical and social implications which tag a complete life. Individuals' background reveals more than events, for they are expressions of built contexts, dimensions and personal consequences [5].

Thereby, the analysis sought to understand the author's autobiographic pathway according to her educational formation by considering the pedagogical process adopted by the course as her main element and teaching methodology.

The results are shown in two stages: the first characterizes the course by addressing its structural, pedagogical and methodological process; the second uses self-assessments as elements to analyze and synthesize the formation process.

\section{Results}

\subsection{Profiling the Post Graduation in Human Development-Holistic Transdisciplinary Approach}

The post graduation course in Human Development—Holistic Transdisciplinary Approach at Nipas-RJ aims

"to benefit individual's necessary changes by taking the whole individual under consideration; and to hold him-her in order to develop transforming actions within the practice area, starting from the Theoretical-experimental proposal of personal, social and environmental Ecologies to the new worldview sustained by the holistic transdisciplinary paradigm, through an educational model”2.

The classes are composted of professionals from different knowledge fields and are also open to undergraduate students as an extension course. Throughout the 21 years of its existence, many of the course's apprentices graduated.

The methodology developed by Unipaz-RJ is centred in Holology and Holopraxis, which are terms developed by Pierre Weil [6] to designate not only the theoretical and experiential study of old and new paradigms pointing out their consequences for human life; but also to highlight how the already set methods enable the synthetic and symbolic experiencing and the immerging in the essence of the Being by developing psychic functions regarding sensing and intuiting.

The course aims to integrate four human intelligences expressed through physical, emotional, intellectual and spiritual quotients. The developed pedagogical process is aligned with education and care by promoting the connection between the two brain hemispheres and facilitating the integration among the four psychic functions (thinking, feeling, sensing and intuiting) and the four states of conscience (watch, dream, deep sleep and transpersonal) through the dynamic exchange among the four forms of human knowledge (science, philosophy, arts and spiritual traditions), thus promoting an interplay among the four intelligence quotients.

The curriculum matrix shows (Table 1) the concern about the integrated formation regarding different knowledge fields of human wisdom; it gives the opportunity to immerse in practice and reflection moments. Several ways of learning are achieved through the methodologies adopted by the course. The graduation course focuses on the need of integrating individuals' intelligence as well as in developing knowledge according to individual levels and it enables understanding the different reality levels and multiple truths of life.

The journey in the course begins from building the comprehension and experience of mankind, nature and society disintegration, through an academic and practical scheme developed by Pierre Weil [7] known as "Wheel of Destruction". The author addresses mankind in its dimensions of mind, body and emotions in her scheme and she aims to contextualize fragmentation from separativity fantasy ${ }^{3}$ [6]. Such separativity is unveiled at birth and

\footnotetext{
${ }^{2}$ www.unipazrj.org.br

${ }^{3}$ The separativity fantasy is a term created by Pierre Weil ([7]: p.22) to express "an imaginary scenario built inside the individuals; it consists in understanding ego as something solid as well as the universe-including living beings—as objects". This imaginary process stablishes a polirazed relationship among individuals and all other things found in the world. As per the author, such division begins in the moment the umbilical cord is cut and the physical separation from the mother takes place.
} 
Table 1. Human Development-Holistic Transdisciplinary Approach in the Post graduation Course Curriculum Matrix.

\begin{tabular}{|c|c|c|}
\hline Module & Work Load & Disciplines \\
\hline $\begin{array}{l}\text { Levels of Conscience and } \\
\text { Reality }\end{array}$ & 84 hours/class & $\begin{array}{l}\text { 1) Introduction to the holistic view } \\
\text { 2) The states of conscience } \\
\text { 3) Live or vegetate-the presence in daily life } \\
\text { 4) The complete looking and listening } \\
\text { 5) Conflict management } \\
\text { 6) The passage visions }\end{array}$ \\
\hline Ecology of being & 84 hours/class & $\begin{array}{l}\text { 1) Old and new therapists } \\
\text { 2) Rite and rituals: archetypal resonance } \\
\text { 3) The nine faces of psyche } \\
\text { 4) The four aspects of conscience } \\
\text { 5) Body and energy awareness }\end{array}$ \\
\hline New Paradigms & 98 hours/class & $\begin{array}{l}\text { 1) Scientific bases to an unifying paradigm } \\
\text { 2) Neuroscience: the light of transdisciplinarity } \\
\text { 3) Brain, mind and the un-formed universe } \\
\text { 4) Holistic transdisciplinary approach } \\
\text { 5) Nutrition: knowing to change } \\
\text { 6) Interactive experiences in the holistic transdisciplinary approach }\end{array}$ \\
\hline Sapiens Traditions & 28 hours/class & $\begin{array}{l}\text { 1) Trans religiosness } \\
\text { 2) Brazilian ancestral tradition: sacred brazilian ancestral tradition }\end{array}$ \\
\hline Sustainability & 14 hours/class & $\begin{array}{l}\text { 1) Eco sustainability } \\
\text { 2) Management and leadership in the holistic transdisciplinary approach } \\
\text { 3) Ethics as sustainability guarantee }\end{array}$ \\
\hline $\begin{array}{l}\text { Scientific Methodology in the } \\
\text { Holistic Transdisciplinary } \\
\text { Approach }\end{array}$ & 28 hours/class & $\begin{array}{l}\text { 1) Awareness construction in the holistic transdisciplinary approach } \\
\text { 2) Awareness production in the holistic transdisciplinary approach } \\
\text { 3) Guidance on the dissertation of the socialization of knowledge course: } \\
\text { webbing the transdisciplinary net. }\end{array}$ \\
\hline
\end{tabular}

stabilises the duality in relationships among individuals, subjects and objects, and subjects and nature.

The segmented vision results from the sensation of separativity between the individual and segments of life surrounding institutionalized knowledge, attitudes in different knowledge fields, different production areas within societies and religions disconnected from fragmentation consequences such as destruction, violence, dual general agreement, hunger, misery, etc. [7].

Overcoming such fragmentation requires investment in the individuals' integration through his-her mind, body and emotions in a way to express this integration in new forms of relationship with nature and society. The counterpoint is found in the elaboration of the "Wheel of life", which enables a positive interaction among individuals, society and nature, after overcoming the fragmentation that separates ways of life [7].

\subsection{Self-Assessment as an Element to Synthesize and Analyse Elements of the Formation Process in Different Levels: Individual, Society and Nature}

According to the self-assessment analysis, I could realize the path I took from the beginning to the end of the graduation process. The first contact with the course and its methodology included the individuals' experience achieved through dynamics and the link between life and its dynamics. The immersion in the course's methodology led to the understanding of deep and complex knowledge through experiencing. It disrupted the content logic focused on concept and theoretical acquisition.

The reasoning on the separativity fantasy takes place during a critical point within the individualism level. I noticed that, as far as the individual is reconnected with the universe and rejects the idea of existential loneliness, it is possible to understand life as integration with the whole universe. Such idea irreversibly changed humans; they broke the polarizations and restabilized bonds with ways of living.

Therefore, I felt invited to join a trip to the challenging Holistic Transdisciplinary approach and to rebuild the "wheel of life" reinforcing peace by the integration between individuals and structures as well as by the energy among science, philosophy, art and spiritual traditions.

It was possible to work with states of consciousness and interpersonal relationship conflicts in other seminars. 
It was done to rescue completeness and harmony within the relationships. We are immersed in the conflicting process of living since birth. Living this process with wisdom requires the ability to change old values by understanding that as we are universal sparkles, they reproduce the same dialectical moment of expanding and contracting.

Thus, this conflict—which is a dimension inherent to life and characterized by opposite strengths-leads to the exercise of listening and acting in the discussion about the problem. Self-listening and valuing messages emitted by the body, feelings, dreams and relationships is the most important and subtle task in the development of new ways of dealing with polarized energies found inside each one of us.

Such exercise bought me the need to immerge in the self-knowledge ocean in order to find our own light and shadow, seeking light by listening to the obscure points that make humans recall nuisances and get in conflict. Differently from what may be imagined, relationships' main vehicle is not the act of saying but that of listening. Listening means to be open to the universe of the other and it brings up a series of elements built since life as a fetus and extended by the cultural, family and religion influence after birth.

Because of the existing inherent duality in life, there are two or more sides to be considered when relationships are under analysis. Opening yourself to this perspective may enable the movement from the person's own place of wisdom and power within relationships.

The integration among different dimensions found inside human beings is the first step to solve conflicts. It leads humans to less travelled paths. Harmony may be lived in different levels, in which good attitudes, thoughts and position taking help structuring a life centred on the peace culture proposition.

By understanding stagnation as the antonym of peace, it is possible picturing the need to live the conciliation inside oneself. Thereby, it is possible to sense the serenity and peace that take the individual to the right place.

Only the transformation movement will allow me to live completeness in my life by being present to access different levels of awareness. Consequently I will develop different perceptions about life.

It is worth highlighting the importance that should be given to body awareness due to the understanding that the individual is part of a macro system which involves and conceives every human being. It is demanding to rescue the body existence and its sensations in order to get to the leading place in life it is the fundamental connection vehicle to achieve a complete existence.

Regardless the formation or professional field, the Initiate Pedagogy ${ }^{4}$ summons people to act differently when facing life by understanding it according to more libertarian concepts and by building new paths able to overcome dualities through relationships.

The concept of normosis ${ }^{5}$ opened a new critical perspective about life. According to the concept, the individual can question values which were inducted and held by humans throughout life and which can turn us into unhappy and numb people.

During the course I reasoned why adulthood is so imprisoning and suffocating. At this point, we forget about the childhood spontaneity. However, by rescuing my backgrounds I could break barriers, thus I may consider myself awaken to a non-numb attitude.

The lessons are focused on changing the individual and on making we seek to connect apprenticeship through experience and reflections in order to understand death as an expression of how we live life, to face daily life and new challenges. I understood it is demanding to know how to deal with conflict in a peaceful and kind way.

I comprehended that peace is achieved through the daily exercise of connecting oneself to the Whole by means of different expressions. Thus, everything is possible if every moment, feeling and thought is lived with consciousness. Through these, we build fullness and harmony. Awakening is a daily exercise expressed in each breath taken and in each dawn in this planet.

Based on the aforementioned, through seminars it was possible consolidating the understanding that each daily act, each seed we plant represent a fruit we harvest in the future, no matter if it happens close to or in the end of life. I am certain that the way live today means one of many possibilities of life expressed in me; affection ties are connections which we bring on and which keep us hanging on love.

\footnotetext{
${ }^{4}$ Initiate Pedagogy is a concept by Crema [8] which refers to the need of a pedagogical process which strengthen the whole development of human beings. This process would work the physical, emotional and cognitive intelligence and also ability scopes of doing, meeting, knowing and relating in harmony with UNESCO educational pillars.

${ }^{5}$ Normosis is a concept by Weil, Leloup and Crema [9] which refers to a dysfunction expressed by the adjustment of violence, disrespect, exclusion, corruption, disaffection and cynicism situation found in the current society. The concept is about finding these situations normal and inherent to society, by making them pathologically adapted in the way they behave and relate to facts and human beings. It naturalizes apathy and the acceptance of unbalances in human's thoughts and actions.
} 
With regard to society and nature levels, graduation courses allow reintegrating knowledge by evoking togetherness between science and humanity. I understood that nowadays society needs to face the death of its models to intervene in reality. Accordingly, I concluded it is essential to be opened to the unknown and to the unpredictable, since wisdom, limited to itself, cannot solve all the problems raised by humanity.

The exercise of ethics, according to the new peace culture and paradigm, depends on the individual's reflection and dialog; it assumes the need to develop different knowledge and act in a way to embrace the other by understanding the different ways of existing in life.

The beginning of species resulted from the total integration of elements that enabled the complexity of all beings and ways of life. Such concept allows reviewing the way to explain reality and why everything and everyone share the same building elements.

Currently, advances in holistic and human ecology studies brought up the need for changing the global awareness about problems afflicting Earth's ecosystem and its operation. Such global awareness intends to show the obvious: everything and everyone (including human beings) living and conceiving this ecosystem is part of a process and regulation chain; i.e., all that there is, is life.

Health is not limited to individual practices such as gymnastics, nutrition and therapy, it is beyond that; it is fundamentally connected to the development of an ecological awareness that tunes humanity with the ecosystem's functionality.

A new ethics requires carefulness from us, regarding knowledge as well as reflection, analyses and talks, so we can live a decent life. Ethics requires the assumption that life is reinforced by individual ideas of happiness and it is necessary to break with prejudice, stigmas, stereotypes, as well as to advocate for personal or specific group concepts to achieve such happiness.

It is worth rescuing ancestral traditions that constitute humans by valuing and integrating them to the formal knowledge, seeking to replace the education role herein described. In other words, it is necessary to be aware and vigilant, redirect inner energies to the overcoming and self-knowledge path.

Transdisciplinarity makes humans see and understand knowledge frontiers as the possibility to dialogue instead of being closed in oneself; it is a way to stop the current learning process applied in colleges and schools.

The herein described exercise requires the non-imposition of ideas and concepts, the use of empty spaces as means to talk and produce knowledge according to new and creative ways distant from the conflicts that try to undertake the core, the reason.

In order for us to achieve a new awareness of life, it is necessary to change the mental and body posture; to deliver, accept, trust and thank so that peace and harmony can be stabilised inside people; and so that the individual is able not to dispute the core with life, but to let life be the core. This is the moment when life itself will conduct humans to fullness. This is the only way we can exercise completeness and the holocentric leadership in our daily life.

\section{Discussion}

According to the syntheses listed in the previous paragraphs, due to self-assessment rescue and analysis. It is possible seeing that the post graduation course led to changes in the individual level because of the self-assessment rescue and analysis and it is expressed by different attitudes towards society and nature.

Such ascertainment deals with the following transdisciplinary assumption: the dialogue among different knowledge fields, the commitment to articulate the multi-referentiality and the multidimensionality of human beings and life itself [10].

According to Mello, Barros and Sommerman ([10]: p. 10), transdisciplinarity "implies transcendental, intellectual and sensitive attitudes beyond oneself and the world". It is about picturing and understanding that life is set by different levels. It is necessary to be open to new information which may come from many plans, cultures and societies, without any hierarchy among them.

Such attitude materializes in different knowledge fields by respecting fundamental traces-strictness, openness, tolerance —and supporting pillars—reality levels, third included logic and complexity [11]—so individuals allow themselves to exercise dialogue, extension, deepness, analysis and synthesis.

Strictness is understood as the importance of substantiating knowledge, language, methodological path, living and sensing; it allows the awareness about itself and the other (subject and nature) by considering established relationships. 
This opening process meets what Morin [12] stressed when he approached the randomness and uncertainty found in reality. That is why it is necessary to be open to the unknown, the unexpected and the unpredictable. It is worth exercising tolerance towards differences and diversity.

In comparison to the construction of a building, respecting and understanding the fundamental traces of transdisciplinary means prepare the land according to guided values. Thus, it is possible to produce knowledge sustained by pillars that, according to Sobrinho [13] and Barbosa [14], require recognizing and knowing that individuals carry a network of levels (physical, emotional, mental and spiritual), psychic functions (thinking, feeling, sensing and intuiting), different awareness states (night watch, dream, deep sleep and transpersonal) as well as a network of acquired knowledge elaborated by the four forms of human knowledge (science, philosophy, art and religious traditions) and their relation with the Other and Nature through the ontonomic dimension of culture (mythic-symbolic; logical epistemic and mysterious). In other words, it is necessary to understand that life behaves in different levels of reality — relative and absolute — which do not allow any kind of diminishment or privilege against the hegemonic view.

Assuming a transdisciplinary attitude requires - according to Blatyta and Rubinstein [15]—respecting human beings in their complteness - body, mind, spirit and emotion - lived in different historical and social contexts; it requires recognizing and valuing otherness within relationships.

Regardless of the object of study, according to Blatyta and Rubinstein ([15]: p. 201), in order to be transdisciplinary it is necessary

“...having an aware attitude which crosses many disciplines: a new ethics which stimulates men to investigate the most different knowledge, meanings, and energetic factors that benefit the respect for human beings and the struggle to enhance quality of life”.

With regard to the scientific scenario, it is possible assuming that this attitude gave birth to the complex thoughts that require the dialogue between knowledge and awareness. It widened the neural web and used more than one line of reasoning. However, the overspecialization model does not allow such movement; it somehow decelerates logic thinking [16].

According to Silva (2005), biological determination itself stops this movement and the neural web extension. However, the relationship of individual's neurological systems with the complex episteme allows the perception of different connections.

Thus, educational formation must enable different ways of apprenticeship by mobilizing physical, mental, emotional and spiritual levels in order to develop wisdom evolution while integrating the individual to itself; so, the renewed sight over life leads to new attitudes in face of contemporary issues.

Barbosa [14] points out the need of teaching to contextualize, substantiate and globalize the role of institutions, imagination, sensitivity and of the body in the exchange of knowledge. Teaching requires breaking up with the hegemonic logic of learning and going beyond the learning how to learn concept; it includes learning how to do and how to live.

According to the transdisciplinary perspective, the act of knowing is not restricted to disciplinary frontiers, but it pushes the connection among disciplines and different meanings that demand methodological flexibility to establish more horizontal relationships.

Learning how to do requires putting creativity in the core, thus it allows recognizing and accessing the strengths by going beyond specialized qualifications which just meet demands from the work market. However, it does not enable the rescuing of the individual's multiple abilities [17].

Living apprenticeship means linking self-knowledge to values and beliefs which were socially built; it also means to be able to pursue otherness by overcoming limitations, allowing horizontal dialogues and valuing the potential of diversity. Otherwise, the power-knowledge relationship would be crystallized, since it induced and still induces to domination, exploitation and disrespect towards all forms of life.

According to Barros ([18]: p. 122), transdisciplinarity means that

"Education is a triple process only navigated by the individual: a stick comes from inside the individual and goes to the external world; the other stick makes the reversal way, goes from the external world to inside the individual; the third one is constituted by the adopted awareness and the retrospection from the influence of heteronormativity and Eco formative".

Thus, according to the transdisciplinary perspective, knowledge has to be generated by means of a process 
capable of reaching the individual in his-her personal formation, therefore possibly creating a relationship with nature and society [18] [19].

It happens by understanding the existential and essential profile of human nature and by the recognition of different reality levels; it turns the development of an ethical attitude possible and highlights all and every way of life. This process includes the observation and experiencing of the other. It is conversational but allows the construction of general agreements and the establishment of responsibilities and respectability [18]. Such ethics makes it is possible to develop safe knowledge about a decent life [1].

The construction of new awareness and practices about oneself and the world includes science and it will be possible at the time mankind awakes up to its self-transformation agent condition, which is expressed by social changes.

According to Galvani [19], self-transformation should not be understood as a process far from heteroformation and Eco formation. After all, it must be understood as the individual's awareness of his-her own functioning, fact that reflects on changes towards nature and the other. Self-development is a process which depends on the relationships established and articulated among people, the environment and knowledge.

Thus, it is possible to understand that the herein analyzed formative process allowed developing the individual in different levels by connecting him-her to society and nature. From this movement on, it becomes possible inserting sciences, wisdom and traditions in the construction of relationship and practices in different professional, sensitive and awakening fields based on the completeness of knowledge.

\section{Conclusions}

The pedagogical process in the Human Development Post Graduation course based on a Holistic Transdisciplinary approach allows apprentices to look for development and complete practices. It enables relationship completion; according to Weil, D’Ambrosio and Crema [20], it refers to the holistic view which encloses sciences, traditions, culture and arts.

The knowledge built over transdisciplinary pillars drives individuals to develop a holistic view. Otherwise, it is not possible to learn the different constituents of reality by experiencing different awareness levels in order to be able to overcome current fragmentations.

Thus, it is crucial to have educational institutions investing in educational formation by dealing with constructive elements from the holistic transdisciplinary paradigm. Thereby, it is possible to influence the individual level along with the development of a global awareness. Such awareness means that the different fields of human knowledge can advance by exercising otherness and responsibility.

\section{References}

[1] Santos, B.S. (2002) A Discourse on Science. 12ª edição, Edições Afrontamento, Porto.

[2] Delors, J., et al. (1998) Education, a Treasure to Discover. Report to UNESCO of the International Commission on Education for the XXI Century. Unesco, Ministério da Educação, Editora Cortez, Brasília.

[3] Bueno, B.O. (2002) The Autobiographical Method and Studies with Teachers of Life Stories: The Question of Subjectivity. Educação e Pesquisa, 28, 11-30.

[4] Silva, A.P., Barros, C.R., Nogueira, M.L.M. and Barros, V.A. (2007) Tell Me Your Story: Reflections on the Life History Method. Mosaico: estudos em psicologia, I, 25-35.

[5] Silva, F.C.R. and Maia, S.F. (2010) Autobiographical Narratives: Interfaces with Research on Teacher Training. VI Encontro de Pesquisa em Educação da UFPI, 2010.

[6] Weil, P. (1987) Neurosis of Paradise Lost. Editora Espaço Tempo, Rio de Janeiro.

[7] Weil, P. (1993) The Art of Living in Peace: Towards a New Consciousness, a New Education. Editora Gente, São Paulo.

[8] Crema, R. (2009) Initiatic Pedagogy: A Leadership School. Editora Vozes, Petrópolis.

[9] Weil, P., Crema, R. and Leloupe, J.Y. (2014) Normosis: The Pathology of Normality. 5a. edição, Editora Vozes, Petrópolis.

[10] Mello, M.F., Barros, V.M. and Sommerman, A. (2002) Education and Transdisciplinary II. Editora TRIOM, São Paulo, 9-27.

[11] Nicolescu, B. (1999) The Transdisciplinarity Manifest. Editora TRIOM, São Paulo. 
[12] Ferreira, M.E.M.P. (2005) University, Culture and Transdisciplinary. In: Friaça, A., Alonso, L.K., Lacombe, M. and Barros, V.M., Eds., Education and Transdisciplinary III, Editora TRIOM, São Paulo, 271-306.

[13] Sobrinho, G. (2014) The Unipaz-RJ Methodology: Holistic Transdisciplinary Approach. www.unipazrj.org.br

[14] Barbosa, D. (2005) The Transdisciplinary Attitude in School Education. In: Friaça, A., Alonso, L.K., Lacombe, M. and Barros, V.M., Eds., Education and Transdisciplinary III, Editora TRIOM, São Paulo, 361-370.

[15] Blatyta, D.F. and Rubinstein, E. (2005) Educational Psychology and Transdisciplinary. In: Friaça, A., Alonso, L.K., Lacombe, M. and Barros, V.M., Eds., Education and Transdisciplinary III, Editora TRIOM, São Paulo, 179-204.

[16] Silva, D.J. (2005) The Complex as a Transdisciplinary Episteme. In: Friaça, A., Alonso, L.K., Lacombe, M. and Barros, V.M., Eds., Education and Transdisciplinary III, Editora TRIOM, São Paulo, 47-76.

[17] Alonso, L.K. (2005) To Know: An Act of Transformation. In: Friaça, A., Alonso, L.K., Lacombe, M. and Barros, V.M., Eds., Education and Transdisciplinary III, Editora TRIOM, São Paulo, 243-270.

[18] Barros, V.M. (2005) Alterity: Autonomy or Ontonomy? In: Friaça, A., Alonso, L.K., Lacombe, M. and Barros, V.M., Eds., Education and Transdisciplinary III, Editora TRIOM, São Paulo, 107-172.

[19] Galvani, P. (2002) Self-Training, a Transpersonal, Transdisciplinary and Transcultural Perspectives. In: Sommerman, A., Mello, M.F. and Barros, V.M., Eds., Education and Transdisciplinary II, Editora TRIOM, São Paulo, 93-122.

[20] Weil, P., D’Ambrosio, U. and Crema, R. (1993) Rumo à nova transdisciplinaridade. Editora SUMMUS, São Paulo. 